\title{
Reflexiones sobre el pintor Lluís Dalmau a propósito de un retablo para Molins de Rei (I45I)
}

\author{
Mercedes Gómez-Ferrer \\ Universitat de València. Departamento de Historia del Arte \\ mercedes.gomez-ferrer@uv.es
}

Recepción: 20/04/2018, Aceptación: 26/06/2018, Publicación: 04/12/2018

\begin{abstract}
Resumen
El presente texto plantea una serie de reflexiones sobre la figura del pintor Lluís Dalmau, uno de los introductores de la pintura gótica flamenca en la Corona de Aragón. El análisis surge a partir de la presentación de un nuevo documento inédito sobre un retablo contratado en I45 I por Isabel de Requesens, esposa del gobernador de Cataluña, Galcerán de Requesens, para la baronía de Molins de Rei (Barcelona). El documento sitúa al pintor realizando este encargo en Valencia, lo que supone un regreso hasta ahora desconocido a su ciudad natal tras haber realizado la tabla de la Mare de Déu dels Consellers, de Barcelona (I443-I445), y el retablo de San Baudilio, de Sant Boi de Llobregat (I448).
\end{abstract}

Palabras clave:

Lluís Dalmau; pintura gótico-flamenca; retablos góticos; pintura valenciana; pintura catalana

\section{ABstract}

Reflections on the painter Lluís Dalmau about an altarpiece for Molins de Rei (I45I)

This article provides a series of new considerations about the painter Lluis Dalmau, one of the most representative figures of the Flemish-Gothic style in the Aragon Crown. We present new documentary evidence about a retable commissioned in I45 I by Isabel of Requesens, spouse of the Catalonian Governor, Galceran of Requesens, for their town of Molins de Rei (Barcelona) while the painter was in Valencia. The document attests to the painter working in Valencia, which proves he returned to his homeland, thus far unknown, after having worked on the retable of the Virgin of the Councillors of Barcelona (I443-I445) and the retable of Saint Baudilio for Sant Boi de Llobregat (I448).

Keywords:

Lluís Dalmau; Flemish-Gothic painting; Gothic retables; Valencian painting; Catalan painting 
$\mathrm{E}$ n los últimos tiempos se ha venido realizando un considerable esfuerzo por comprender y ordenar el difícil capítulo de la pintura gótica flamenca en los años centrales del siglo $\mathrm{xv}, \mathrm{y}$ en particular el referido a las manifestaciones artísticas de los territorios de la antigua Corona de Aragón. En este periodo se dan cita una serie de maestros que han conocido de cerca el ars nova flamenco, ya fuera por el traslado y la importación de pinturas, dibujos, miniaturas o tapices, ya fuera por la presencia en nuestras tierras de artistas procedentes o formados en Flandes, o por los propios viajes de pintores a zona flamenca, hechos que contribuyen a cambiar radicalmente las formas, las técnicas y los modos pictóricos ${ }^{1}$. Aunque algunas personalidades van perfilándose poco a poco, como los pintores valencianos Jacomart y Reixach, y otros comienzan a tener más claras las cronologías, como Bartomeu Baró, muchos siguen sumidos en el anonimato, como el Maestro de Bonastre o el Maestro de la Porciúncula, y otros son totalmente cuestionados, como el maestro Luis Alimbrot, por ceñirnos exclusivamente al panorama valenciano. Con el presente texto, nuestra intención es aportar una nueva reflexión sobre uno de los maestros más importantes del periodo referenciado, el valenciano Luis o Lluís Dalmau (act. I 425 -I 46I $)^{2}$, a partir de noticias inéditas y de una reconsideración de documentación ya conocida.

\section{Lluís Dalmau y los inicios de la pintura flamenca en Valencia}

No es nuestra intención realizar una revisión completa del perfil biográfico de Luis Dalmau, quien, al ser uno de los principales pintores de este periodo, cuenta con una importante bi- bliografía desde la identificación de su autoría en el caso del retablo de la Mare de Déu dels Consellers, de Barcelona ${ }^{3}$, y desde que Tramoyeres ${ }^{4}$ llamara la atención sobre las noticias que lo relacionaban con la comisión de viajes a Flandes por encargo del rey Magnánimo y otras noticias. Pero, a pesar de que puede parecer que contamos con bastante información sobre este maestro, aún se mantienen muchas incógnitas sobre su vida y sus obras, con grandes vacíos en el conjunto de una relativa dilatada cronología, que se extiende desde I 425 hasta I46r. El tiempo vivido en Flandes sigue siendo difuso; lo realizado en Valencia a su regreso, totalmente desconocido; el motivo de su traslado a Barcelona, poco claro, y la escasez y el alcance de los encargos y la aparente desigual calidad de las obras conservadas también llama la atención. Por todo ello, consideramos que el hecho de que aún podamos ofrecer una noticia inédita sobre un retablo encargado al pintor Lluís Dalmau tras un regreso a su ciudad natal, Valencia, cuando se le creía afincado en Cataluña, a pesar de que no será posible una identificación con una obra conservada, es de por sí importante para poder seguir clarificando muchos aspectos de este periodo y del trasiego existente entre Valencia y Barcelona a mediados del siglo xv.

Aunque la mayor parte de la bibliografía ${ }^{5}$ sitúa el periodo documentado del pintor Lluís Dalmau a partir de 1428 - en el momento en que, por mandato del rey, se le paga para marchar a Castilla-, hay que notar que su vinculación con la casa real es anterior, puesto que ya el 22 de diciembre de 1425 pintaba seis escudos de madera dorados y rojos para una de las puertas delos aposentos dela segunda torre del palacio del Magnánimo, que se reconstruía en el Real de Valencia ${ }^{6}$. Por lo tanto, nos movemos en el entor- 
no real desde esta fecha, con encargos relacionados con labores decorativas que se presuponen a este tipo de pintores. Del 16 de agosto de 1428 es el pago de 330 sueldos por el viaje al que se le había comisionado en Castilla, que tuvo que producirse durante los meses anteriores y en el que se le mencionaba como «Luis Dalmau pintor de la ciutat de Valencia» ${ }^{7}$. Al poco tiempo, en diciembre de ese mismo año, se consigna su nombre en las cuentas vinculadas al rey con el título de «pintor de casa real», con un salario fijo ${ }^{8}$. El 6 de septiembre de I43 I consta su desplazamiento a Flandes por mandato del rey ${ }^{9}$, aunque no disponemos de noticias seguras del total de tiempo transcurrido en la estancia ni de los lugares recorridos, que siempre se ha supuesto que tuvo que ser relativamente amplio, por la dependencia mostrada a su regreso con la obra de Jan van Eyck. Revisada la documentación del entorno real, por ahora no se ha encontrado otra noticia hasta el 7 de julio de I436, en que, de nuevo y tras su regreso a la misma ciudad de Valencia, se le sitúa realizando las funciones que se pueden presuponer a un pintor de la corte: la pintura y el dorado de elementos de una de las tiendas de campaña reales, la «vibra, pal, tallador y pom», con la correspondiente entrega de tres muestras o dibujos de la vibra y uno de un rat penat, que debieron ser bastante elaboradas, ya que tardó is días en prepararlas; la pintura de la silla de madera y las armas en los escabeles para el lugarteniente real, el futuro Juan II, pagadas el 3 de enero de I437, o una imagen de San Miguel para la clave de otra de las tiendas del rey, cobrada el i I de febrero de I438, que fue valorada por Reixach, Gonçal Peris y García Sarriá en 220 reales de Valencia ${ }^{10}$.

Ya advertimos que ha llamado la atención que, como pintura figurativa, solo pudiéramos documentar una cortina con el tema de la salutación para colocar delante de una imagen en la capilla del castillo de Xàtiva en $1436^{11}$. Sin embargo, esta capilla estaba necesitada de un nuevo retablo y, como sabemos, a ella se trasladará en I 440 un retablo de los Gozos de la Virgen que inicialmente había pintado Joan Reixach para el pavorde de la catedral y confesor del rey Antoni Sanç en $1437^{12}$. No se ha localizado por ahora ninguna otra noticia relacionada con retablos, ya fueran o no del entorno del rey, de particulares $u$ otras instituciones que hubiera en Valencia en aquellos años. Por este motivo, el dato que presenta en julio de 1438 a Manuel Dalmau, mercader, dispuesto a alquilar una casa en Barcelona, a la espera de que su hermano se desplazase a esa ciudad, siempre se ha puesto en relación con el traslado posterior de Lluís a Barcelon $\mathrm{a}^{13}$, que, con total seguridad, no podemos documentar hasta I443. Podríamos haber supuesto que tendría más sentido que Manuel hubiera contado con su otro hermano Galcerán, que también era mercader de profesión, ya que, al compartir trabajo, es más fácil pensar que «les dues botigues» que tenía alquiladas fueran para los mencionados negocios. Dicho trabajo conjunto de los dos hermanos mercaderes ya lo llevaban realizando desde al menos el año I 430 , en que se dedicaban al comercio de vino con Mallorca ${ }^{14}$. Pero Galcerán se debió quedar en Valencia, como se deduce de los documentos relacionados con el matrimonio de su hija en I 460, del que son fiadores el propio Lluís y Manuel, y en los que se indica a Galcerán Dalmau como habitante de la ciudad de Valencia ${ }^{15}$.

Resulta, por tanto, sorprendente ver que un pintor al que se ha enviado en embajada a Flandes por mandato del rey y que regresa tras adquirir unas habilidades muy apreciadas no reciba ningún encargo importante a su vuelta. Es cierto que el Real valenciano aún estaba en obras en los años de I435-I440 y que disponía de dos capillas, la principal de las cuales, la de Santa Catalina, tenía un retablo que no se decidió cambiar hasta $\mathrm{I} 458$. La capilla real en el convento de Santo Domingo no había sino empezado su construcción, y su retablo también se retrasaría muchísimos años. Pero en Valencia muchos eran los nobles que estaban comisionando retablos para capillas privadas ubicadas en los principales conventos, parroquiales o en la catedral. Quizá alguna de las pinturas anónimas puedan considerarse de Lluís Dalmau, pero por el momento no hemos encontrado ninguna noticia documental que lo relacione con obras importantes, salvo las indicadas que lo sitúan siempre como pintor decorativo. Sorprende también que no fuera él el pintor elegido por el Magnánimo para trasladarse a Nápoles en I440, cuando lo podría haber hecho desde Valencia, si aún seguía allí, o desde Barcelona, si ya se había trasladado a la Ciudad Condal, y que fuera Jacomart el que fue llamado a pesar de las reticencias que en un primer momento pareció mostrar.

Podemos quizá entender que esos años de ausencia de Dalmau en Flandes le habían alejado de la clientela que aún encargaba piezas en los obradores de los familiares del pintor Pere Nicolau, que suponían un epígono de la pintura del gótico internacional, o en otros talleres que irrumpían con fuerza. Así, por un lado, se mantenían los talleres de un maduro Jaume Mateu ( 1382 -I 452 ), sobrino de Nicolau; de un Gonçal Peris Sarriá en el final de su carrera ( $†$ I $45 \mathrm{I})$, y de un prometedor García Pérez de Sarriá (†I440), sobrino de Gonçal. El fallecimiento del joven García Pérez de Sarrià en mayo de I440 abrió el paso a otros pintores, entre los que sobresale Reixach, que había comenzado con algunos 


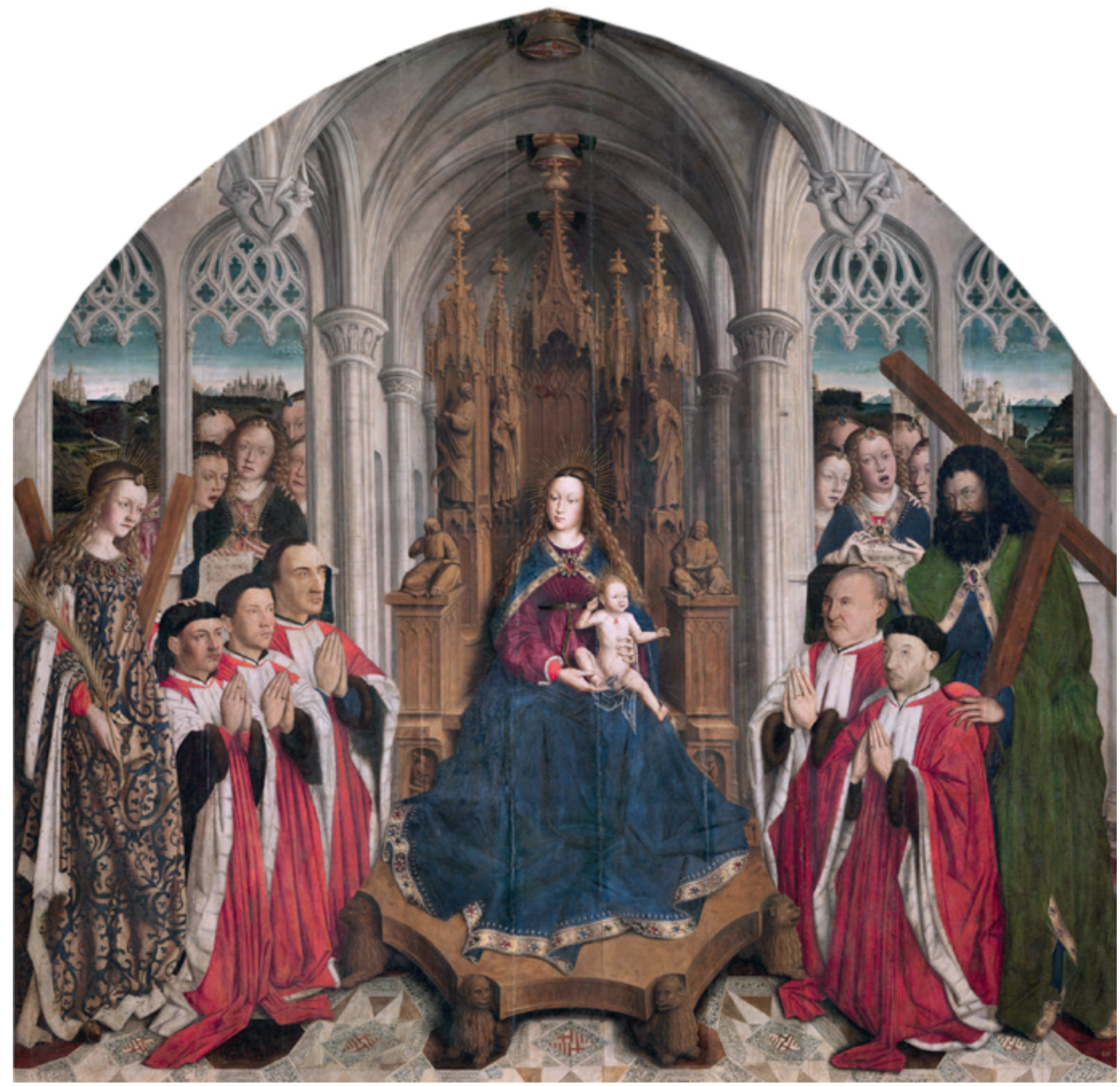

Figura 1.

Lluís Dalmau, retablo de la Mare de Déu dels Consellers, 1445 (MNAC).

encargos propios en I 437 y que concluiría los inacabados de Pérez Sarriá, como el de los Santos Juanes para la capilla de Joan Aguilar, en el convento de predicadores. O Jacomart, que, entre el momento de ser requerido por el rey en Nápoles en I 440 y su definitiva partida en I 442, había firmado unos cuantos contratos de retablos que también deja inconclusos. Además, acababa de instalarse en la ciudad Lluís Alimbrot, flamenco, llegado hacia I439, que supuestamente también debió recibir encargos, aunque por ahora son pocas las noticias seguras sobre dicho maestro ${ }^{16}$. Todos los talleres mencionados se nutrían de jóvenes aprendices, y en este sentido queremos apuntar a esa efervescencia la formación que iniciaba un jovencísimo Bartomeu Baró (I422-I48I), con I7 años y medio, en febrero de I440, cuando se comprometía con el taller de García Sarriá por espacio de cuatro años y medio, afirmamiento que se vio truncado por la muerte de este a los pocos meses ${ }^{17}$. Apuntamos la posibilidad de que Bartomeu Baró se trasladara entonces al taller de Luis Alimbrot, y con ello pretendemos también dar un poco de consistencia a la figura de dicho artista, que ha quedado totalmente puesta en entredicho. En I 443, cuando fallece na Dolça, madre de Baró, se cita entre los testigos a Luis 
Alimbrot, señalando que este la conoce, hecho que indica un contacto entre las dos familias que quizá podemos explicar por una relación de aprendizaje ${ }^{18}$. Estas noticias también adelantan la cronología de Baró y lo sitúan formado a partir de I444, cuando hubo alcanzado la mayoría de edad, rebajando aún más la posible actividad como pintor independiente que ya se había corregido adelantándola a $\mathrm{I} 45 \mathrm{I}^{19}$ y relacionándolo de forma directa con todos estos maestros de mediados de siglo.

Quizá esta competencia empujó a Dalmau a abandonar Valencia, quizá fueron motivos familiares, como el hecho de unirse a su hermano en su aposentamiento en Barcelona, incluso se ha especulado con la posibilidad de que realizara un nuevo viaje a Flandes entre 1438 y I $443^{20}$. Sea como fuere, se había considerado que, a partir de la fecha del encargo del retablo de la Mare de Déu dels Consellers (figura I) para la capilla de la Casa de la Ciudad de Barcelona en I443, o quizá antes, Dalmau se había afincado y permanecido ya definitivamente en la Ciudad Condal, aunque mantenía relaciones con Valencia, como demuestran sus contactos con pintores de esa ciudad, de los que hablaremos a continuación. No creemos que el hecho de que los consellers mencionen que se tenía que buscar y encontrar el mejor pintor que se pudiera («que en cerchar e trovar se pogués») sea indicativo de que ya residía en Barcelona, porque las noticias sobre la calidad de los pintores corrían entre los territorios de la Corona de Aragón, y no significa que solo se hubiera buscado entre los mejores pintores de la Ciudad Condal. Por otro lado, también llama la atención que, en el contrato con los consellers, no se mencione a Lluís Dalmau como habitante de Barcelona, sino simplemente como pintor. Quizá ese dato pueda explicar también la rotundidad de la firma en la parte baja de la tabla, la cual se puede considerar una carta de presentación de un pintor en la ciudad. Algo parecido a lo sucedido con la firma de Reixach en el retablo de Santa Úrsula (I468) destinado a una capilla de la iglesia del monasterio de Poblet, lugar algo más alejado de la producción habitual del pintor, que así se daba a conocer, y quizá también similar a la intención de Bartolomé Bermejo al firmar la tabla del San Miguel de Tous en la misma fecha. A nuestro entender, tampoco se ha profundizado excesivamente en la traza supuestamente entregada por Dalmau que contiene el proyecto del retablo y que se conserva en el Archivo Histórico de la ciudad de Barcelona. Desde luego es de por sí un hecho bastante excepcional, ya que, aunque «les mostres» se suelen mencionar en los contratos notariales, no son tantas las del siglo xv que han llegado hasta nosotros ${ }^{21}$. Sin embargo, creemos que «lo exemplar ja mostrat als honorables consellers» no significa necesariamente que fuera algo totalmente ajeno y novedoso, propio del pintor, sino absolutamente dependiente de los que lo encargaron, que le debieron dar todas las indicaciones y presumiblemente los elementos escritos en la traza. Atendiendo a la terminología y a la correlación existente entre el texto de la capitulación del retablo y el dibujo, no parecen corresponderse con un pintor valenciano, puesto que difícilmente hubiera escrito las palabras retaula o ystorias ${ }^{22}$.

Estas reflexiones nos deberían conducir a no dar tan por supuesta la presencia de Dalmau en Barcelona desde $\mathrm{I} 438$ como se ha querido imaginar, y plantearnos la posibilidad de que hubiera seguido residiendo en Valencia hasta las fechas inmediatas a su traslado a la Ciudad Condal, así como reconsiderar que, para ser llamado y distinguido como el mejor pintor, debía de haber realizado alguna obra relevante que acreditara esta valía que por ahora desconocemos.

Todas las noticias documentales posteriores, cuyo alcance también cabrá matizar, siempre habían sido referentes a encargos en tierras catalanas. Desde 1447 en adelante, el retablo de Sant Boi de Llobregat (I448), el de la capilla de San Antonio en Santa María del Mar (I449), el retablo de San Agustín (I452), pinturas en la capilla de San Elmo en el convento de Santa Clara de Barcelona (I454), el retablo de Santa Cecilia situado en Mataró (I457) y otras noticias de diversa consideración hasta I46I hacían presuponer que Lluís Dalmau no había abandonado Barcelona. Los datos que presentaremos a continuación vienen a indicar que no fue así y que durante un cierto tiempo regresaría a Valencia, donde tuvo un taller desde el que realizó al menos un retablo, si bien iba destinado a tierras catalanas.

\section{El retablo de Molins de Rei para los Requesens}

Los archivos valencianos siguen ofreciendo datos documentales inéditos que están contribuyendo a arrojar algo de luz a dicho panorama ciertamente complejo de la pintura valenciana del siglo xv. Sigue habiendo nuevas noticias que a veces nos alteran el discurso establecido y que nos obligan a reflexionar. El documento que damos a conoce ${ }^{23}$ nos advierte de la presencia de Dalmau en Valencia el I4 de julio de I45 I, «Valencie de presenti conmorans». El artista se compromete a terminar en el plazo de cuatro meses un retablo «con ciertas figuras», que en aquellos momentos se encontraba realizando para Isabel de Requesens - esposa de Galcerán de Requesens (I400-1465), caballero, gobernador de Ca- 


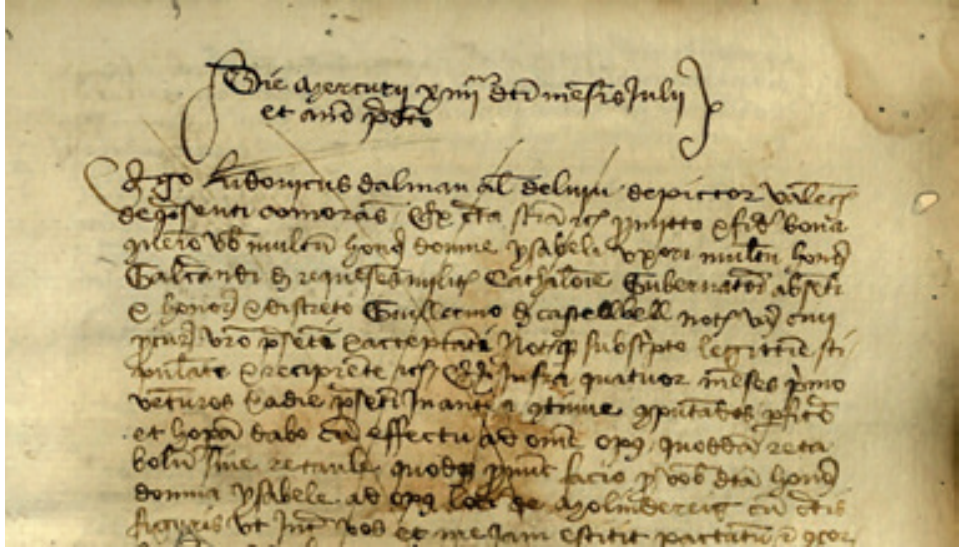

Figura 2

Fragmento del documento de Lluis Dalmau e Isabel de Requesens, 1451 (ACCV).

taluña - y que iba destinado al lugar de Molins de Rei, tal y como estaba pactado entre ambos (figura 2). La obligación se planteaba ante el notario Guillem de Castellbell ${ }^{24}$, procurador de la anterior que estaba ausente, y ante los testigos a quienes había mostrado más de la mitad del retablo ya pintado, según lo que había sido capitulado entre las partes. Cuando el retablo estuviera terminado, debía ser llevado por tierra o mar a su propio riesgo y gasto hasta la ciudad de Barcelona o hasta el lugar de Molins de Rei, según se le indicara por parte de Isabel, bajo pena de 50 florines de oro. Dalmau reconocía haber recibido ya 95 libras, I 2 sueldos y 6 dineros, moneda de Valencia que se correspondía a I 50 florines de oro, a razón de i 2 sueldos y 9 dineros por florín. Esa cantidad de i 50 florines era la que la mencionada Isabel, mediante dos cartas remitidas en distintas fechas a su procurador, había ordenado pagar a Dalmau por el motivo indicado. En atención a lo dicho, Lluís Dalmau daba como fiador a Lluís Talamanca ${ }^{25}$, cambista de Valencia, sobrino suyo, quien estaba presente y aceptaba, y se comprometía al igual que Dalmau con todos sus bienes de forma solidaria. Los testigos eran dos ciudadanos de Valencia, Pere Dauder ${ }^{26}$ y Joan Ferri. Dicho contrato se daba por cancelado y lineado ${ }^{27}$ el I de julio de 1452 por deseo de Guillem de Castellbell, quien dijo haber recibido una carta de su representada, para que no pudiera perjudicar a dichos Dalmau y Talamanca ni a la dicha Isabel, por lo que el retablo en esta fecha se daba por concluido y entregado ${ }^{28}$.

No hemos podido localizar el contrato del retablo, que no se encuentra en el protocolo anterior a esa fecha de 1450 , por lo que quizá se firmó ante otro notario valenciano o en I449, protocolo que no se conserva ${ }^{29}$. Por otro lado, tampoco sería descartable que dicho contrato se hubiera firmado inicialmente en Barcelona, ya que los Requesens se encontraban residiendo allí, y que, ante el traslado de Dalmau a Valencia, hubieran tenido que contar con la intervención de su procurador, Castellbell, que era el encargado de muchos de sus asuntos valencianos. Tampoco hemos encontrado ninguna otra ápoca de pago que haga referencia a este retablo en los siguientes volúmenes, pero el hecho de que ya estuviera medio realizado en julio, y a falta de cuatro meses, nos hace sospechar que a fines de $145 \mathrm{I}$, o al menos en julio de 1452 , que es cuando se da por cancelado el contrato, ya estaría terminado. Al acabarse en esos meses o un poco más tarde, Dalmau regresaría de nuevo a Barcelona. En cualquier caso, a pesar de que no conocemos la iconografía ni el lugar exacto en Molins de Rei para el que fue encargado este retablo, es mucha la información que este documento nos ofrece.

Por un lado, nos advierte que Dalmau, tras los años vividos en Barcelona, que transcurren desde al menos I 443 hasta I 449, regresa temporalmente a Valencia por espacio de uno a tres años, tiempo que se puede considerar suficiente para la terminación de un retablo, y lapso que nos ofrece la información documental. Si atendemos a la cronología conocida de Dalmau, el 23 de julio de $\mathrm{I} 449$, siendo habitante de Barcelona, cobraba 66 sueldos por pintar una parte del retablo de San Antonio encargado por la testamentaría de Francisco Pich, presbítero de la iglesia de Santa María del Mar, para su capilla funeraria en esa iglesia ${ }^{30}$. El documento es una ápoca y la cantidad correspondiente es una tercia, pero no sabemos si la última; en cualquier caso, corresponde a una intervención menor. Pensamos que el pintor dejaría Barcelona poco después de esta fecha. Sabemos que el 20 de julio de i 452, unos días después de la cancelación del contrato de los Requesens, se le contrataba de nuevo en Barcelona para la realización del retablo del gremio de blanquers en la iglesia de San Agustín, encargo que no cumplió, y que se volvería a contratar por completo por parte de Jaume Huguet ${ }^{31}$.

En realidad, el contrato de los Requesens nos devuelve a un Dalmau retablista, ya que, ciertamente, las noticias que conocemos a día de hoy, posteriores a la tabla de la Mare de Déu dels Consellers, nos habían dejado un panorama bastante reducido sobre su actividad. Prácticamente el único gran retablo era el de Sant Boi de Llobregat, porque el resto de obras planteaba muchas dudas. El retablo de San Baudilio conservaba la tabla principal, a la que se han incorporado además otras dos que también debieron pertenecer al conjunto: la que muestra la decapitación del santo (figura 3), que se da por seguro que forma parte de él ${ }^{32} y$ 
que en la actualidad está expuesta en el MNAC tras su restauración, y otra que se encuentra en una colección particular y que trata sobre la presentación de un santo ante el juez, que es más dudosa, pero que, por sus características, también se ha considerado una obra posible de este mismo retablo ${ }^{33}$. Se trata, por tanto, de un trabajo documentado, ya que se conserva la fecha del contrato, aunque carecemos de referencias sobre la cantidad cobrada por Dalmau y sobre las características de la capitulación ${ }^{34}$. De una cronología bastante próxima a la tabla de los consellers, y a pesar de su calidad, ha servido para evidenciar las dificultades de Dalmau en composiciones para las que no contaba con modelos exactos y el alejamiento de las fórmulas eyckianas exactas a los pocos años de haber realizado su obra principal.

El resto de obras, sin embargo, son menos elocuentes. La citada de Santa María del Mar, revisada la transcripción documental, en realidad era una parte de un retablo, como hemos visto, por lo que se contrató por una cantidad muy pequeña. El retablo de San Agustín no parece ni siquiera que lo empezara, ya que fue contratado por completo con posterioridad por el pintor Jaume Huguet. El de la capilla de San Elmo para los marineros en el convento de Santa Clara era una obra de policromía para una capilla que ya contaba con un retablo que se había encargado años antes a Bernat Martorell ${ }^{35}$. En esta línea de trabajos de policromía en capillas se había apuntado la posibilidad de adjudicar a Dalmau la pintura de la capilla de Sanxa Ximenis de Cabrera en la catedral de Barcelona, en razón de las similitudes formales que presenta con otras obras de Dalmau. Realmente tan solo contábamos con el retablo para la capilla de Santa Cecilia de la parroquia de Mataró, capitulado el 22 de marzo de I 457 por valor de 50 libras barcelonesas cobradas en su totalidad el is de diciembre de I459, lo que nos advierte de unas dimensiones presumiblemente discretas ${ }^{36}$. Todo el resto de noticias estaban relacionadas de nuevo con obras decorativas de carácter menor.

A lo largo de los tres años en los que Dalmau pudo residir en Valencia, entre julio de I 449 y julio de I452, se hizo cargo al menos del retablo de los Requesens, del cual sabemos que, en julio de 145 I, estaba a la mitad cuando lo mostró a los testigos citados y por el que había cobrado una cantidad de 90 libras, cifra nada desdeñable, aunque tampoco conocemos si corresponde al total acordado. Es posible que no, porque esta cantidad ya la había cobrado a la mitad de la obra al parecer en dos pagos, y quizá aún le pudo faltar la última de las tercias. Por tener una referencia de los precios pagados en torno a esas fechas, diremos que 90 libras

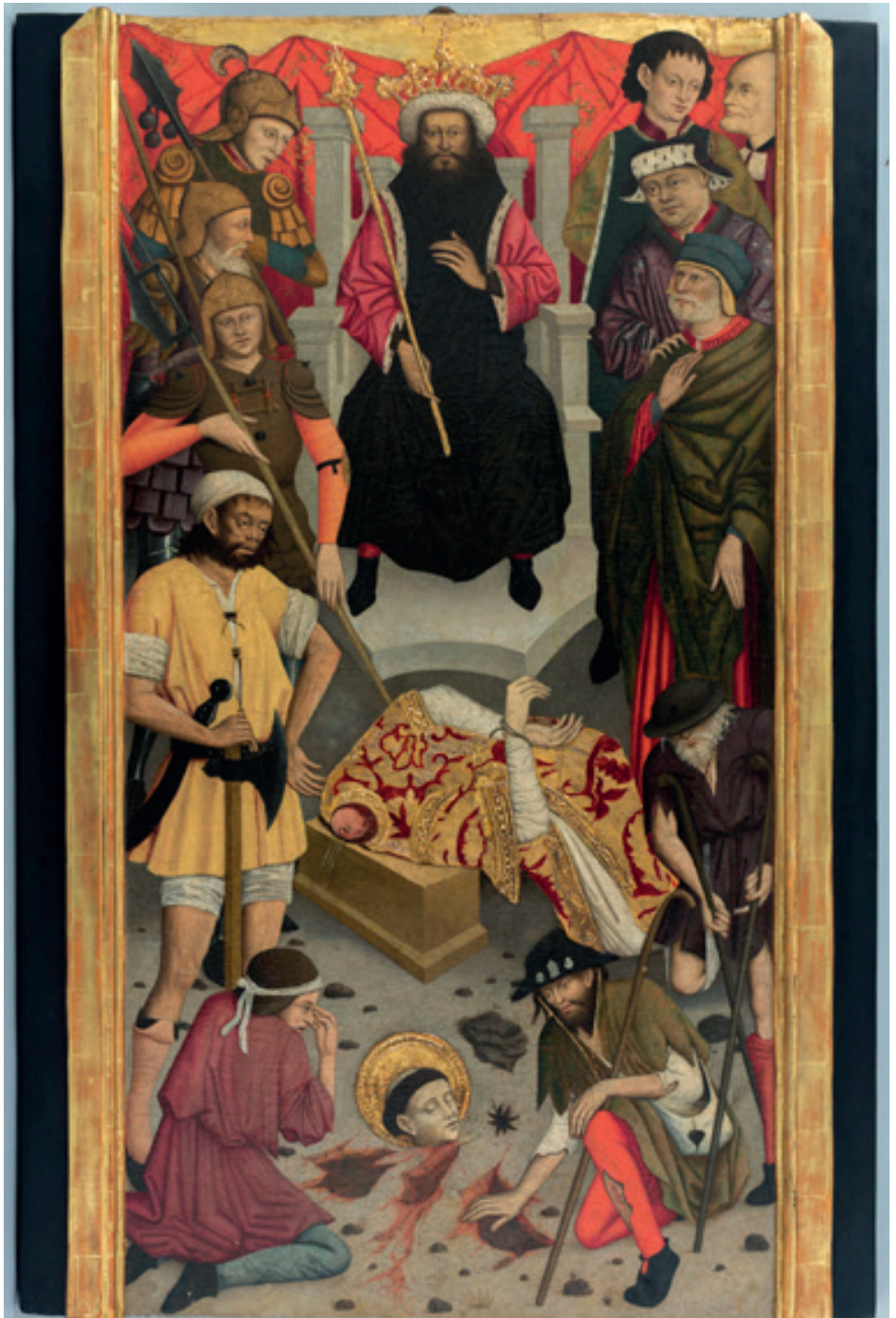

Figura 3.

Lluís DAlmau, Decapitación de San Baudilio, retablo de Sant Boi de Llobregat, 1449 (MNAC).

de moneda valenciana es, por ejemplo, el precio pagado a Reixach en fecha estrictamente coetánea por el retablo para la capilla de Santa Ana del cardenal Alfonso de Borja en Xàtiva, aunque cada caso es particular y no podemos realizar comparaciones estrictas.

En ese contrato valenciano se reconoce a Lluís Dalmau con el alias Delviu, un apodo que nos hubiera planteado dudas de no ser porque también se le documenta así en Barcelona en un documento posterior, del 20 de abril de I453, escrito también en latín. «Ludovicus Dalmau alias Delviu» es fiador y presumiblemente uno de los pintores encargados de policromar dos entremeses para las fiestas del Corpus de Barcelona, el de la Creación del Mundo y el de la Natividad, así como la paloma del entremés de la Anunciación por encargo del presbítero Joan Çalom $^{37}$. Desconocemos si esta referencia tiene relación con un topónimo, como se ha querido 
explicar $^{38}$, por ejemplo: Viu de Linás, pueblo pirenaico en la comarca del Sobrarbe en Huesca, o Viu de Llevata, en el distrito de Tremp, Léri$\mathrm{da}$, por cuanto sabemos que Dalmau era valenciano. También se ha mencionado la posibilidad de que adoptara dicho alias para diferenciarlo de otros artistas de apellido Dalmau, aunque por los datos que tenemos el único pintor coetáneo es Antoni Dalmau, que, al tener distinto nombre, no debería ofrecer ninguna duda. Aquel documento de 1453 era el único conocido hasta la fecha en el que se utilizaba dicho alias. El que publicamos ahora es otro texto que viene a confirmar que lo empleaba, aunque desconocemos realmente su significado.

Este encargo nos sitúa a Dalmau trabajando para los Requesens en un momento en que era una de las familias más influyentes y que contaba aún con el apoyo real. Galcerán de Requesens y Santacoloma, gobernador de Cataluña desde I 432, había recibido la baronía de Molins de Rei en 1430 por concesión de Alfonso el Magnánimo ${ }^{39}$. El i7 de febrero de I43 I casaría con la valenciana Isabel Juan Soler, hija de Bernat Joan, señor de Tous y nieta de Pere Soler, maestro en medicina y físico del rey. Realmente, es ella la que parece estar al frente del encargo y no su esposo, hecho que nos podría haber ofrecido alguna pista si hubiera estado en relación con alguna vinculación más personal de la esposa de Galcerán y con algún lugar concreto, pero por el momento desconocemos cuál pudo ser. En la elección del pintor también pudo pesar el hecho de compartir procedencia valenciana con Isabel Juan o la consideración previa de Dalmau como pintor real, ya que Requesens era un personaje totalmente ligado a la figura del rey Magnánimo, puesto que entró muy joven a su servicio, recibió una serie de cargos relacionados con la vida en la corte, como el de ujier real, y lo acompañó en la organización militar de la guerra contra Juan II de Castilla (I429-I 430), lo que explica la donación de la villa de Molins de Rei. En cualquier caso, dada la azarosa vida delos Requesens, el contrato se produce en uno de los momentos de ascenso político y social, en una situación política convulsa que acabará finalmente con su caída en desgracia años más tarde. Un gobernador que se había enfrentado a consellers y diputados elegía como pintor para su retablo al flamante Lluís Dalmau, que hacía tan solo unos años había retratado a estos mismos consellers en la tabla de la capilla de la Casa de la Ciudad. Uno de estos enfrentamientos se había producido precisamente en I450, cuando acogió y protegió en Molins de Rei a Joan de Torrelles o Torroelles, señor de la villa de Sant Boi de Llobregat, que había sido acusado de practicar el corso contra los mercaderes barceloneses y de desafiar armado a uno de los consellers $^{40}$. Solo unos años antes, Torrelles había estado detrás del encargo del retablo de San Baudilio a Dalmau, cuya financiación no estuvo exenta de problemática.

Como posibles lugares de destino del retablo, que no se indican en el documento, se encuentran las iglesias de la población y del entorno de Molins de Rei y el palacio de los Requesens de esa villa. En cuanto a las iglesias, cabe mencionar la parroquial de San Miguel de la propia población, que era sufragánea de la Santa Creu d'Olorda, en aquel momento la parroquia principal, y la de Sant Bertomeu de la Quadra, pequeño núcleo habitado muy cercano a Molins de Rei. Lo que conocemos de estas iglesias por el momento no permite afirmar nada sobre el destino del retablo.

En las visitas pastorales de I 435 y I 440 a Molins de Rei solo se alude a la imagen de San Miguel cubierta por una cortina en el altar mayor ${ }^{41}$, mientras que en la de ${ }_{4} 484$ sí se hace mención de un retablo, pero sin más detalle. Sabemos que el testamento de Galcerán de Requesens, dispuesto en Cervera el 28 de junio de I457, indicaba que deseaba ser enterrado en esta parroquia $^{42}$, sin más disposiciones que aludieran a una capilla funeraria de forma específica ya dotada de retablo de alguna advocación concreta o de la que hubiera que dotar. En cualquier caso, su fallecimiento, sucedido en Valencia cuando ya se habían producido los hechos que conducirían a su exilio, se retrasaría hasta 1465 . El de su esposa no se produjo hasta I484, y en las disposiciones testamentarias del año I48I no hay alusión alguna a esta parroquial. Isabel indicaba que, si fallecía en Valencia, quería ser enterrada en la capilla de San Lorenzo del convento de predicadores, donde se encontraban sus abuelos Isabel y Pere Soler, y si lo hacía en Barcelona que se le sepultara en el monasterio de monjas de San Jerónimo, para el que entregaba también una cantidad de roo libras de ayuda a la obra y reparación ${ }^{43}$. No parece, por tanto, que tuviera una especial predilección por una capilla en Molins de Rei para la que, en unos años anteriores, hubiera mandado realizar un retablo. Nos hace dudar también que fuera para esta iglesia el hecho de que el ${ }_{1} 3$ de marzo de I 526 se firmaban capitulaciones para un nuevo retablo con una imagen de una escultura de San Miguel realizada por Bernat Balle y pinturas con historias del santo encargadas a Jaume Fontanet por Hipólita de Requesens ${ }^{44}$. En realidad, habría transcurrido poco tiempo para haber desechado un retablo anterior de calidad, por lo que es más probable que fuera realizado ante la falta de una obra importante en el altar mayor. En cuanto a la iglesia de la Santa Creu 
d'Olorda, los retablos conocidos son del siglo $\mathrm{XVI}$, sin que se tenga constancia de importantes retablos anteriores ${ }^{45}$, ya que, en 1484 , el altar mayor aún seguía únicamente con una cortina con la imagen de la Resurrección. De la iglesia de Sant Bertomeu de la Quadra ${ }^{46}$, sabemos que sí conservaba un retablo del siglo $\mathrm{xv}$ dedicado al santo titular y que se encuentra custodiado en la actualidad en el Museo Diocesano de Barcelona, aunque sin el bancal original, hoy perdido ${ }^{47}$. El retablo fue considerado por Post genéricamente como de la escuela de Huguet, aunque actualmente se adscribe a un seguidor de los Vergós hacia fines del siglo $\mathrm{xv}^{48}$.

La mención de que la obra era para Molins de Rei y no para estas otras poblaciones nos hace mirar hacia el palacio que los Requesens poseían en la villa. Aun cuando el lugar de residencia de los Requesens en Barcelona fue el importante Palau Menor, también tuvieron en la población de su señorío un palacio que debieron mejorar a partir de la toma de posesión de la villa. El palacio, del que quedan muy pocos restos, fue casi totalmente demolido en el siglo $\mathrm{XIX}^{49}$. Sabemos de la importancia del edificio y desde luego pensamos que debía estar bien dotado, por cuanto llegó a albergar visitas de los Reyes Católicos e incluso la estancia durante tres meses del emperador Carlos V durante la peste que tuvo lugar de i 5 i 9 a I 520 .

En el palacio consta la existencia de una capilla de la que se conoce que tenía dos tramos con dos arcos y preciosas claves y de la que queda una puerta ${ }^{50}$ (figura 4). Pero las descripciones de su interior proceden de un inventario de la tardía fecha de 1607 en el que se menciona la presencia de un retablo, sin más indicación ${ }^{51}$. En cualquier caso, aunque la documentación hubiera ofrecido más detalles, al desconocer la temática del encargo a Dalmau, resultaría difícil relacionarlo con el documento que presentamos. Por otro lado, no tenemos tampoco constancia de ningún retablo conservado que se pueda adscribir a Lluís Dalmau como procedente de esta población.

A pesar de no poder identificar el retablo propiamente dicho, sí podemos constatar una serie de hechos. El más importante es que el taller valenciano de Lluis Dalmau estaba activo, aunque quizá por un tiempo muy limitado, ya que la expresión «de presenti conmorans» parece aludir a una situación bastante provisional y localizada en el tiempo. La referencia más explícita al contacto con Valencia la certifica la relación que tenía Dalmau en estos años con el pintor Bartomeu Almenar. Este artista era hijo de un pintor valenciano de nombre Francisco que había sido cortinero y que estaba documentado entre I 40I y I444 $4^{52}$. Bartomeu Almenar seguía en

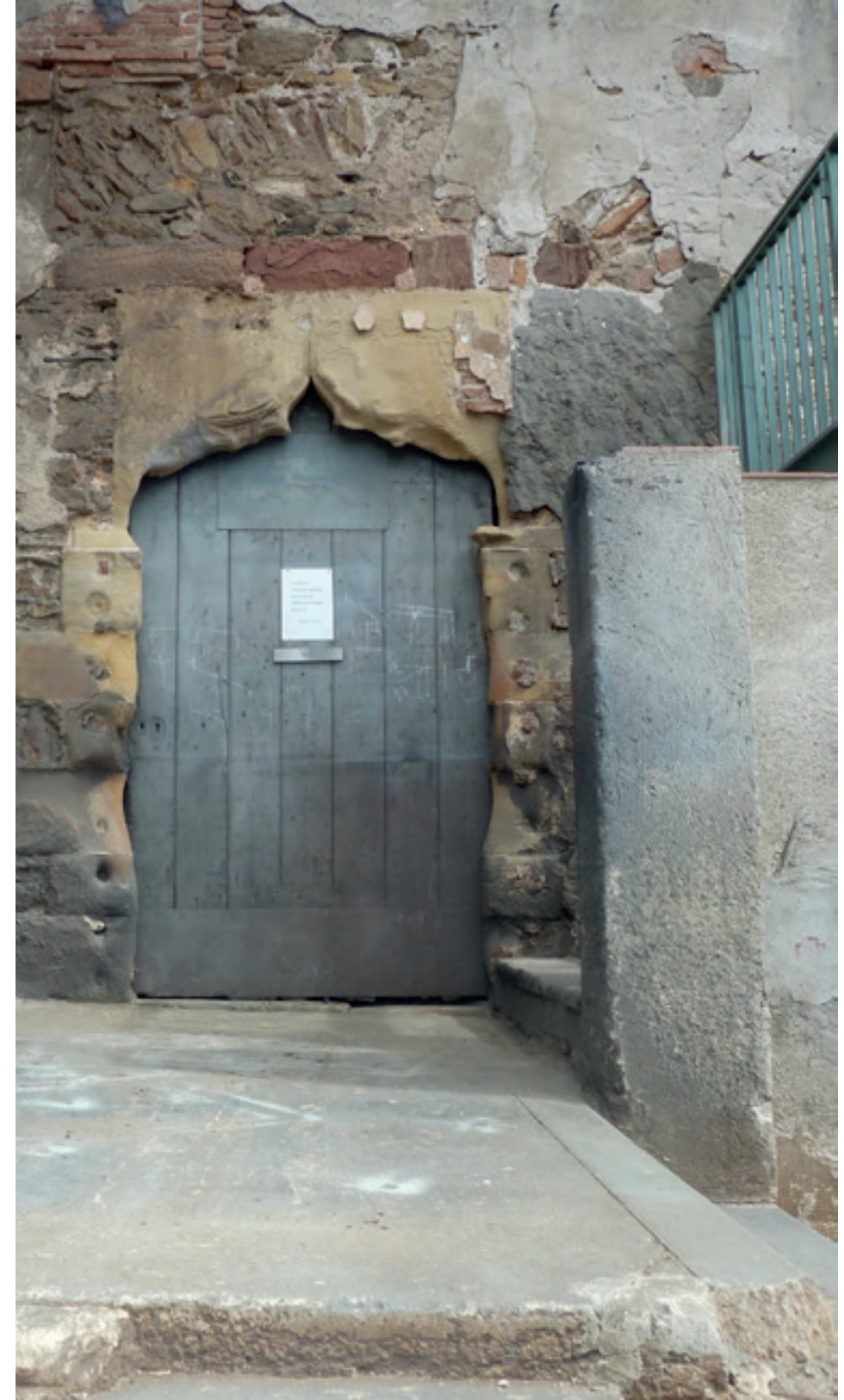

Figura 4.

Puerta de la capilla del Palacio de los Requesens en Molins de Rei.

Valencia en I444, cuando ya Dalmau estaba en Barcelona pintando la tabla de la Mare de Déu dels Consellers. Sin embargo, el 26 de noviembre de I447 aparece documentado junto a Dalmau en Sant Boi de Llobregat, cuando ambos actúan como testigos de los poderes otorgados por el caballero Joan de Torroelles ante el doncel Luis Ortiz. Torroelles es el que está detrás de la financiación del retablo de San Baudilio, cuando se debía iniciar el proceso para su realización, que se retrasó por cuestiones económicas hasta el is de septiembre de $1448^{53}$. Pero la colaboración de Almenar con Dalmau, que ha servido para indicar las diferencias estilísticas entre las varias tablas pertenecientes a este retablo, habrá que 
matizarla mucho, ya que, por documentación inédita, sabemos que esta solo pudo ser posible durante un tiempo muy breve. Bertomeu Almenar consta documentado de nuevo en Valencia el 3 de enero de $1449^{54}$.

Que el regreso a Valencia de Dalmau en I449-I450 pueda deberse a la posibilidad de volver a contar con Almenar o con otros pintores locales en su taller es una de las propuestas. No sabemos si Almenar luego se trasladó de nuevo con Dalmau a Barcelona en la década siguiente, porque las noticias posteriores sobre dicho pintor son de Valencia a partir de febrero de I46I y hasta la tardía fecha de $\mathrm{I} 485^{55}$, lo que nos hace presuponer que se trataba de un joven en los primeros años de relación con Dalmau. Ninguna de las noticias conocidas de Almenar lo vinculan a retablos o a obras de peso. Tampoco parece que pueda relacionarse con pintura significativa Gaspar Gual, el otro pintor de presumible origen valenciano, cortinero o decorador, presente en Barcelona al menos desde $1455^{56}$, con el que Dalmau había fundado una compañía para proveer las naves reales de pendones de trompetas y banderas, y con el que tuvo un litigo en I46r. Este pintor se ha identificado con el valenciano Gaspar Gual, que en I435 estaba pintando a las órdenes de $\mathrm{Mi}$ guel Alcañiz en la bóveda del presbiterio de la catedral valenciana los ángeles con los instrumentos de la pasión. Es un pintor decorador del que tampoco se tienen muchas más noticias ${ }^{57}$. Otro pintor al que se le ha supuesto una relación con Dalmau, pues actúa como testigo en un documento de este de i 8 de diciembre de I447, cuando Dalmau nombra como procurador suyo a Joan Sech, causídico de Barcelona ${ }^{58}$, es Pere Arnal, un pintor también de tono menor que podría estar vinculado a su taller, aunque no necesariamente.

Los años que se suceden entre I 449 y I 452 son especialmente significativos para la pintura valenciana. Jacomart acababa de regresar de Nápoles y se encontraba estableciendo de nuevo un taller que, a partir del 22 de junio de I 448 , contaba con la presencia de Jaume Vergós como aprendiz. Contrataría varias obras, algunas fallidas, como el retablo de Museros ( 1450 ), pero otras realizadas, como las intervenciones en el retablo mayor de San Martín ( 4 52), o el retablo de Pere Lorach, también para una capilla funeraria en San Martín (I 455) ${ }^{59}$. Otros talleres, como el de Reixach, uno de los más activos, continuaba con encargos importantes. Entre ellos, el más significativo es el de la capilla de los Borja en Xàtiva, por el que cobraba ápocas el 2 I de junio y en diciembre de 1452 , pero seguramente contratado a comienzos de 1452 . En fechas también estrictamente coetáneas, Bartomeu Baró contrataba el retablo de los santos Cosme y Damián para el presbítero Damiano Moltó, fechado a partir del i de marzo de I45 I. Es decir, unos años en los que de nuevo la competencia era grande, pero, incluso así, la demanda parecía suficiente como para permitir que estuvieran en marcha tantos talleres de retablistas. Quizá el contrato de Dalmau, aun siendo en Valencia, se debía corresponder con una demanda realizada desde Barcelona, donde se encontraban residiendo los Requesens, en aquellos momentos alternando estancias entre su villa de Molins de Rei y la propia de la Ciudad Condal. Aunque en esta época sea habitual el traslado de los pintores entre ciudades, no dejan de sorprendernos estas idas y venidas, cuando parecía que el éxito alcanzado por el retablo de la Mare de Déu dels Consellers, de Dalmau, le hubiera granjeado una cómoda estancia en la Ciudad Condal, inicialmente con menos rivales que en Valencia, pero donde empezaban a prosperar talleres que acabarían acaparando el mercado, como el de Jaume Huguet. Lo cierto es que, por razones que desconocemos, regresó a la que presuponemos su ciudad natal y realizó desde allí dicho trabajo, que nos muestra a un Dalmau más activo de lo que hasta entonces se conocía.

Por otro lado, a pesar de la importancia de dicha noticia, seguimos sin poder resolver la incógnita de los anónimos pintores de aquellos momentos y sin poder asignar nuevas obras al quehacer de Dalmau. Las afinidades estilísticas entre algunas de las obras que se sabe fueron realizadas en Valencia y los escasos trabajos documentados y conservados de Dalmau no son suficiente argumento para poder relacionar obras y autores. Tendremos que seguir confiando en que la investigación de archivo nos pueda ayudar a solventar todas las dudas que seguimos manteniendo sobre la pintura de este periodo. 


\section{Apéndice documental}

Archivo de Protocolos del Colegio del Corpus Christi de Valencia

Notario: Pere Masó, signatura: 22859

I 4 de julio de I $45 \mathrm{I}$

Die mercurii XIIII ${ }^{a}$ dicti mensis Julii et anno predicto.

Ego, Ludovicus Dalmau alias Delviu, depictor, Valencie de presenti comorans, ex certa sciencia, etc., promitto et fide bona convenio vobis, multum honorabili domne Ysabeli, uxori multum honorabili Galcerandi de Requesens, militi, Cathalonie Gubernatori, absenti, et honorabili et discreto Guillermo de Castellbell, notario, Valencie civi, procuratore vestro, presenti et aceptanti notarioque subscripto legittime stipulante et recipiente, etc., quod infra quatuor menses primo venturos a die presenti in antea continue computandos, perficero et hoperam dabo cum effectu ad omne opus, quoddam retabolum sive retaule quodque pro nunc facio pro vobis dicta honorabile domna Ysabele ad opus loci de Molin de Reig cum certis figuris, ut inter vos et me jam estitit pactatum et concordatum, etc., sub pena quinquaginta florenos auri, etc.; fiat executoria largomodo cum submissione et renunciacione fori, etc.; quodquidem retabolum vobis, dicto honorabile Guillermo de Castellbell, in presentia notarium et testium subscriptorum, hostendo iam plus de medietate depictum; quodque retabolum perfectum infra dictos quatuor menses portare aut portari facere per terram aut per mare ad mei periculum et expensas ad civitatem Barchinone aut ad dictum locum de Molin de Reig, vobis dicte honorabile domne Ysabeli super hoc electione servata, etc., sub dicta pena L florenorum predictorum, etc.; cum executoria largomodo ut supra, etc. Et ulterius confiteor habuisse et recepisse, voluntati mee realiter numerando, a vobis dicta honorabile domna Ysabele, absente, per manus vestri dicti honorabili Guillermi de Castellbell, presentis, procuratoris vestri, nonaginta quinque libras duodecim solidos sex denarios monete regalium Valencie pro valore centum quinquaginta florenorum auri, ad racionem XII solidos
VIIII denariorum pro quolibet floreno, cum tantum valeant floreni antea hodiernis temporibus in presenti civitate Valencie. Quos CL florenos vos, honorabilis Ysabel iam dicta, cum duabus vestris missivis litteris sub diversis kalendariis factis et directis dicto Guillermo de Castellbell, procuratori vestro, iussistis michi dari et solvi [sic] racione predicta, etc.; unde renunciantes scienter omni excepcioni, etc.; et pro predictis attendendis dono vobis fidanciam et principalem obligatum qui mecum e sine me teneatur et obligatus sit vobis et vestris in predictis, venerabilem Ludovicum Talamancha, campsorem Valencie, nepotem meum, presentem et aceptantem, etc.; renunciantes nos, dicti Ludovicus Dalmau et Ludovicus Talamancha, benefficio dividendarum actionum, etc,; et foro Valencie, etc.; et pro hiis complendis uterque nostrum insolidum obligamus omnia bona nostra et utriusque nostrum insolidum, etc., vobis, dicte honorabili domne Ysabeli, absenti, procuratore vestro presenti ac subscripto notario stipulanti, etc. Et denique promittimus et juramus ad dominum Deum, etc., non impetrare guidaticum, etc., sub pena CC solidorum, etc.; fiat latis, etc. Actum est hoc Valencie, etc.

Testes: honorabiles Petrus Dauder et Johannes Ferri, cives Valencie.

[... fuit certa] ceda prout [jacet ...n] papiro auctoritatis dicto procuratore.

Post modum, vero die sabbati intitulata prima Julii et anno $\mathrm{M}^{\circ} \mathrm{CCCC}^{\circ} \mathrm{LII}^{\circ}$, lo dessús insert contracte et obligacions [sic] és stat cançel-lat e lineat de voluntat del dit en Guillem de Castellbell en lo dit nom, com ell digué haver hauda letra de la dita senyora sa principal, ab la qual li mana que cancel.le lo dit contracte. E per consegüent li plau aquell esser cancel-lat e lineat en tal manera que als dits en Luis Dalmau alias [Delviu] e en Luis Talamancha noure no puixa, ne al dit En Castellbell [en] el dit nom aprofitar en alguna manera. Presents testimonis foren lo honorable mossèn [Guerau] Bou, cavaller, et en Johan Vives, scrivent de València. 
* Este trabajo se enmarca en el proyecto I+D financiado por el Ministerio de Economía, Industria y Competitividad, HAR201783070-P, Geografías de la movilidad artística: Valencia en Época Moderna.

1. La historiografía viene recogiendo en los últimos años cada vez más claramente todas las relaciones entre el mundo flamenco y la pintura en la Corona de Aragón durante el siglo xv. Importantes fueron las aportaciones de F. BENITO y J. Gómez Frechina (2001), La clave flamenca de la pintura valenciana, Valencia, Generalitat Valenciana, y R. CoRnudella (2009-2010), «Alfonso el Magnánimo y Jan van Eyck: Pinturas y tapices flamencos en la corte del rey de Aragón», Locus Amoenus, 10, p. 39-62. También lo relativo a sus viajes a la península Ibérica en $\mathrm{M}$. PARAda (2016), El viaje de Jan van Eyck de Flandes a Granada 14281429, Madrid, La Ergástula.

2. Luis, Luys o Lluís en valenciano o Ludovicus en latín.

3. J. Puiggarí (1870), «Un cuadro de Luis Dalmau del siglo XV», $L a$ Ilustración Española y Americana, XIV (9) (25 de abril), p. 188-189, y S. Sanpere i Miquel (1906), "Los cuatrocentistas catalanes», L'Avenç, p. 205-207.

4. L. Tramoyeres (1907), «El pintor Luis Dalmau: Nuevos datos biográficos», Cultura Española, 6, p. 553-580.

5. Una de las consideraciones bibliográficas más completas se encuentran en F. Ruiz QuesadA (2007), «Lluís Dalmau y la influencia del realismo flamenco en Cataluña», en M. C. LACARRA (2007), La pintura gótica durante el siglo $X V$ en tierras de Aragón y en otros territorios peninsulares", Zaragoza, Institución Fernando el Católico, CSIC, p. 243-297.

6. M. Gómez-Ferrer (2012), El Real de Valencia: Historia arquitectónica de un palacio desaparecido, Valencia, Institució Alfons el Magnànim, p. 73, procede del Archivo del Reino de Valencia (ARV), Mestre Racional, signatura: 9206, 22 de diciembre de 1425, «A Luis Dalmau, pintor, per pintar sis senyals reals que eren ja cavats de fusta ab or e vermell, a obs de la porta de la sala de la segona torre».

\section{L. Tramoyeres (1907), «El} pintor...», op. cit., p. 559-560. A partir de entonces han sido muchas las consideraciones sobre el alcance de este viaje y los posibles contactos establecidos por Dalmau con Jan van Eyck en su embajada de Flandes a Portugal en 1428, fundamentalmente el trabajo clásico de C. Pemán (1969), Juan van Eyck y España, Cádiz, Museo Provincial de Bellas Artes de Cádiz. Sin embargo, parece que se debe descartar un contacto inicial entre Dalmau y Van Eyck en embajadas anteriores fechadas en 1426 y 1427 a la Corona de Aragón con paso por Valencia. Ver las recientes consideraciones al respecto de este conocimiento de la obra de Van Eyck en Valencia en R. CORNudeLLA (2016), «Un ritratto scomparso di Alfonso el Magnanimo, l'influenza eyckiana a Valencia e l'enigma Jacomart», en Uno sguardo verso Nord, Padua, Il Poligrafo, p. 123132. Y hay también una cierta dificultad para explicar un posible encuentro de ambos en Lisboa. Ver R. Cornudella (2009-2010), «Alfonso el Magnánimo...», op. cit.

\section{L. Tramoyeres (1907), «El} pintor...», op. cit., Los pagos se van repitiendo entre diciembre de 1428 con un salario de 370 sueldos, en marzo, junio y octubre de 1429 se repiten los pagos con salarios de 340 sueldos.

9. L. Tramoyeres (1907), «El pintor...», op. cit., p. 570, reproduce el documento de este mandato, en el que ya consta como pintor de la casa del señor rey.

10. Estas noticias que no reprodujo L. Tramoyeres fueron dadas a conocer de forma parcial por J. SANChis Sivera (1929), «Pintores medievales en Valencia», Archivo de Arte Valenciano, p. 40. El primer documento fue reproducido de forma más completa por L. Cervveró (1971), «Pintores valentinos», Archivo de Arte Valenciano, p. 30, pero incluso así faltaba la indicación de los quince días empleados en la realización de los dibujos, que ha sido comprobado al revisar el documento en el ARV, Bailia, Ápocas, 45, 7 de julio de 1436. El resto de datos se conocen desde que fueron publicados por J. Sanchis Sivera.

11. M. Gómez-Ferrer (2006) «Jacomart, revisión de un problema historiográfico", en L. HerNÁNDEZ Guardiola, De pintura valenciana (1400-1600): Estudios y documentación, Alicante, Instituto Juan Gil-Albert, p. 71-99.

12. M. Gómez-Ferrer (2010), «Nuevas noticias sobre retablos del pintor Joan Reixach (act. 1437
1486)», Archivo de Arte Valenciano, Valencia, XCI, p. 39-52.

13. A. Durán i SAnpere (1973), Barcelona i la seva història, Barcelona, tomo II, p. 146. En realidad, en ningún momento del documento se menciona el nombre del hermano.

14. ARV, notario: Vicent Çaera, 24 de octubre de 1430. Ambos hermanos, Galcerán y Manuel Dalmau, están relacionados con el comercio de «decem botis vini vermelli» entre Valencia y Mallorca.

15. L. Tramoyeres (1907), «El pintor...», op. cit., p. 576, y Archivo de Protocolos de Barcelona, (AHPB), notario: Guillem Jordá, 216/64, 20 de diciembre de 1460. Sabemos que Úrsula era hija de Galcerán, citado como ciudadano de Valencia que había estado casado con Rosa, difunta, y sus tíos eran los fiadores. En cualquier caso, la hija casaba con Gabriel Sabater, mercader de Barcelona, por lo que entendemos que las relaciones de los Dalmau entre Valencia y Barcelona continuaron siendo muy fluidas durante todos los años.

16. Una de las obras que la historiografía tradicional atribuía a Luis Alimbrot, el tríptico de los Rois de Corella conservado en el Museo del Prado, ha sido ahora puesto en entredicho y atribuido al denominado Maestro Collins, un iluminador de Amiens presente en Brujas en 1440 , con lo que las obras asignadas a Alimbrot quedan sin autoría fehaciente. Sobre este tema, véase $S$. Nash (2014), «The Myth of Louis Alincbrot: Relocating the Triptych with scenes from the Life of Christ in the Prado", Boletin del Museo del Prado, 32 (50), p. 70-95.

17. Documento inédito procedente del Archivo del Colegio del Corpus Christi de Valencia (ACCV), Protocolos, Bertomeu Batalla, signatura: 12 de febrero de 1440, Bartomeu Baró hijo de Pedro Baró tendero ciudadano de Valencia, de 17 años y medio poco más o menos se afirmaba con García Pérez de Sarriá, pintor de la misma ciudad, por espacio de cuatro años y medio. Uno de los testigos del documento era el también pintor Joan Pérez.

18. ACCV, Protocolos, Bertomeu Batalla, libro de testamentos, n. $^{\circ}$ 1514, Testamento de Na Dolça, mujer de Pere Baró, deja sin herencia a Margalida, su hija, casada con Nadal Colom, y sin embargo deja todos sus bienes a Berthomeu Baró, pintor, hijo suyo. Entre los testigos, «Luis Alimbrot, flamenc, 
pintor», que dijo conocer a la dicha testadora. El documento no tiene fecha, pero se sitúa entre uno que está datado en febrero de 1442 y otro en el día 29 de junio de 1443. Por el lugar ocupado en el volumen parece más próximo al mes de mayo o junio de 1443.

19. M. Gómez-Ferrer (2009), «Aportaciones sobre el pintor valenciano Bartomeu Baró (doc. 14511481)», Ars Longa, 18, p. 81-89.

20. Posibilidad apuntada por F. Ruiz Quesada (2007), «Lluís Dalmau...”, op. cit.

21. J. Berg-Sobré (1989), Behind the Altar Table: The development of the Painted retable in Spain, 1350-1500, University of Missouri Press, p. 288-290. Encontramos una transcripción actualizada del documento y de la traza en F. Ruiz Quesada (2006), «Lluís Dalmau», en L'art gòtic a Catalunya, Pintura III, Barcelona, Enciclopèdia Catalana, p. 56-59.

22. En los numerosísimos contratos valencianos de esta época la variante utilizada para el retablo es retaule, nunca retaula. En cuanto a las historias, puede transcribirse generalmente como istories o ystories, pero prácticamente en ningún caso como ystorias. Por eso dudamos del grado de independencia de Dalmau en dicha traza, así como de la posible indicación de todo el programa por parte de alguno de los consellers. Dicha ortografía corresponde a una variante del catalán oriental de Barcelona, que comportaba una vacilación típica a la hora de transcribir la vocal neutra.

23. Ver apéndice documental. Agradezco al profesor Jose María Cruselles la revisión de la transcripción documental y las orientaciones proporcionadas para su correcta interpretación.

24. Guillem de Castellbell es un notario valenciano del que se conservan varios protocolos en una serie bastante irregular en la que faltan muchos volúmenes, en el Archivo de Protocolos del Colegio del Corpus Christi de Valencia, desde el año 1423 hasta el 1453, y que además se documenta como procurador de varios nobles, como los Moncada, posiblemente porque había emparentado con la familia de los Vilaragut. La mujer de Guillem de Castellbell, de nombre Úrsula, era hermana de Isabel, mujer de Juan Jerónimo de Vilaragut, señor de Masalavés. Ver ACCV, Protocolos, Pere Masó, signatura: 22853, 24 de abril de 1455.
25. Desconocemos las relaciones familiares exactas entre los Dalmau y los Talamanca. De este cambista sabemos que muere ab intestato antes de 1468 dejando tres hijos: un Pere Talamanca, también cambista, y dos menores de edad en el momento del fallecimiento, Eleonor y Miguel. ARV, notario: Jaume Salvador, signatura: 1994, 23 de agosto de 1474. Se indica que hay constancia fechada el 4 de junio de 1468 , en los registros de la curia de 1474, en la décima mano. Dichos registros para ese año solo se conservan a partir de la mano duodécima y no existen los volúmenes anteriores.

\section{Desconocemos la profesión} de este Pere Dauder, pero lo continuamos viendo documentado relacionado con la familia Dalmau, cuando Manuel Dalmau, mercader, de regreso a Valencia en 1465, le vende un esclavo de 11 años de edad (ACCV, Protocolos, Tomás Nicolau, signatura: 26461, 2 de octubre de 1465).

27. Terminología utilizada en la cancelación de otros contratos valencianos, que en ocasiones dan más detalle porque señalan el pago completo de la pieza y su entrega. ACCV, Protocolos, Lluís Guerau, signatura: 27183, 28 de diciembre de 1422, se firma un contrato entre Joan de Alcaraz, bordador y unos vecinos de la villa de Llíria para la entrega de un paño. El 1 de junio el contrato «fuit cancellatum e lineatum», y se detalla la entrega del paño y la recepción del dinero.

28. En la nota de cancelación se dice que el contrato deja de tener valor porque así lo desea la parte acreedora, es decir, la que debía recibir el bien (Isabel de Requesens) y que se cancela para que Dalmau y Talamanca no puedan verse perjudicados (es decir, que se les exija por segunda vez el pago de una deuda que ya han pagado). Son Dalmau y Talamanca los interesados en que el contrato se cancele, porque se trata de quienes han contraído la obligación, y por tanto quienes han solicitado al notario y a la otra parte que se proceda a dicha cancelación. Se indica expresamente que también se cancela el documento para que el procurador Castellbell y su cliente (Isabel de Requesens) no puedan aprovecharse de él en forma alguna, es decir, reclamando al deudor del bien un segundo pago que ya ha sido realizado. Por ello se entiende que es una nota de terminación del contrato.

29. A pesar de encontrarse en proceso de digitalización, hemos podido consultar todos los volúmenes conservados de este notario en el archivo gracias a la atención de Salvador Ferrando, y no hemos encontrado ninguna otra referencia a Lluís Dalmau.

30. Este dato, publicado por J. M. Madurell i Marimón (1946), El arte en la comarca alta de Urgell, Barcelona, Anales y Boletín de los Museos de Arte de Barcelona, p. 332, se había venido repitiendo en la bibliografía habitual sobre Dalmau y se había indicado que era la obra importante de un retablo completo. Revisado el documento en AHPB, notario: Narcis Bru, 141/5, 23 de julio de 1449 , leemos el precio exacto del encargo y de qué se trata: «sexaginta sex solidos monete Barchinone de tercio michi debitos pro pingendi quandam partem retabuli», lo que rebaja su importancia.

31. A. Duran i Sanpere (1929), El retaule de San Agusti dels Blanquers de Barcelona, Barcelona, Impremta R. Tobella.

32. Ver las importantes contribuciones de F. Ruiz Quesada (1997), «Una nova taula documentada de Lluís Dalmau, d'origen santboià», Butlletí de la Reial Academia de Belles Arts de Sant Jordi, XI, p. 113-127, y Francesc Ruiz QueSADA (2000), «La taula de la mort de San Baldiri, de Lluís Dalmau: Confirmació de l'autoria i de l'origen santboià de l'obra», Butlletí de la Reial Acadèmia de Belles Arts de Sant Jordi, 14, p. 135-149.

33. Dada a conocer por Gómez Frechina y citada por F. Ruiz QueSADA (2007), en «Lluís Dalmau...», op. cit., p. 260-261, que pertenece a la colección Gerstenmaier.

\section{J. M. Madurell i Marimón}

(1946), El arte..., op. cit., p. 351-352, publicó las noticias documentales referentes a la firma del contrato para el retablo con el carpintero Jaume Roig el 13 de septiembre de 1448 y la firma con Dalmau dos días después, pero del que solo se conoce el encabezamiento, por lo que no sabemos los pagos y plazos.

35. Mencionadas en J. M. MADURELl y Marimon (1946), El arte..., op. cit., p. 332.

36. Documento publicado en el apéndice documental de $\mathrm{S}$. SANPERe i Miquel (1906), «Los cuatrocentistas catalanes», tomo II, documento XIV.

37. Esta noticia fue citada por J. Puiggarí (1880) en Noticias de 
algunos artistas catalanes inéditos: Apuntes leídos en la sesión de 17 de junio de 1871, Memoria de la Real Academia de Buenas Letras de Barcelona, 3, p. 74-103, p. 85-86, sin indicar referencia ni transcripción documental exacta. Había sido recogida en la bibliografía posterior sin más indicaciones, pero procede en realidad de A. BALAguer (1871), «De las antigas representacions dramáticas y en especial dels entremesos catalans", en F. PeLAY y BRIZ, Calendari Català del any 1871, Barcelona, Estampa de lo Porvenir, p. 56-66. Sobre la posibilidad de que Dalmau, además de ser testigo de este pago, fuera autor de las pinturas de los entremeses puede consultarse en J. YARZA (19831985), «Artista-artesano en el gótico catalán», Lambard, III, p. 160, y J. Molina i Figueras (1996), «La participació dels pintors en les cerimònies i espectacles quatrecentistes a Barcelona i Girona», en F. MAssip, Formes teatrals de la tradició medieval, Barcelona, Institut del Teatre, p. 173-179.

\section{S. SANPERE (1906), «Los} cuatrocentistas...», op. cit., p. 245.

39. Sobre los Requesens en Molins de Rei, ver J. Fernández (2005), Politica, societat i economia en una vila catalana medieval: Molins de Rei, 1190-1512, Ajuntament de Molins de Rei.

40. C. Martí (1952), «El cavaller Joan de Torrelles, noble i corsari», en Notes històriques de la vila de Sant Boi de Llobregat, Sant Boi de Llobregat, Biblioteca Popular, p. 25-31.

41. J. Jordì i Capdevila (1993), Molins de Rei: La parròquia de Sant Miquel Arcàngel, Molins de Rei, Parròquia de Sant Miquel Arcàngel, realiza un documentado recorrido por la historia de la parroquia. No obstante, se han comprobado los libros de visitas pastorales del Archivo Diocesano de Barcelona, volumen 16, f. 49v., visita de 3 de agosto de 1435, donde, en referencia al altar mayor, tan solo se menciona que es de San Miguel y que está bien. La visita de 1447 en el f. 438v. que no ofrece mayor información. En el volumen 21, f. 107r., visita del 20 de julio de 1484, que es la única que recoge la palabra retablo en el altar mayor, indicando que se cubría por medio de una cortina: «cohoperendum retabulum».

42. B. Pedemonte i Falguera (1929), Notes per a la història de la Baronia de Castellvell de Rosanes, Barcelona, Elzeviriana, p. 435.

43. ACCV, Protocolo, Bertomeu de Carries, signatura: 20423, 22 de mayo de 1481 .

\section{J. M. JoRdÀ I CAPDEvila} (1993), Molins de Rei..., op. cit., p. 49-56.

\section{J. M. JordÀ I CAPdevila} (2002), Santa Creu d'Olorda: Història d'un poble que no pogué reeixir, Parròquia de Santa Creu d'Olorda.

46. J. JoRdÀ I CAPDEvila (1990), Sant Bartomeu de la Quadra i la Rierada, Barcelona, Gráficas Fomento, p. 54-55.

47. Se restauró en 2010 y fue expuesto durante unos meses del 2011. Actualmente no se encuentra entre las piezas expuestas. Ver B. Montobbio y J. M. Martí i BoNET (2011-2012), «Exposició del retaule de San Bertomeu», Taüll, 34 (diciembre-enero), p. 14-15.

48. R. C. Post (1938), A History of Spanish Painting, VII. Part 1, Harvard, p. 412-413. El autor advierte de la rigidez de los modelos y lo sitúa en una cronología de fines de siglo.

49. E. Ripoll (1999), «El Palau dels Requesens de Molins de Rei», L'Espai, 2, p. 36-44, y C. Solans (1999), «L'enderroc del Palau dels Requesens», L'Espai, 2, p. 45-55.

50. J. M. Jordà i Capdevila (1993), Molins de Rei..., op. cit., p. 87, cita las referencias sobre la capilla del palacio de los Requesens, que mencionó mosén Bartomeu Rafols en 1808 y Francesc Rodón, que coinciden con los breves apuntes indicados sobre las claves esculturadas y los dos tramos. En estos textos nada se dice de un retablo.

51. J. M. Jordà I Capdevila (1993), Molins de Rei..., op. cit., p. 87. Documento procedente de la carpeta 53 del archivo de los Requesens: «Item en la capella son retaule, palis i tovalles dolentes, uns amits i dues casulles dolentes amb stola».

52. J. SAnchis Sivera (1930), "Pintores medievales en Valencia», Archivo de Arte Valenciano, Valencia, p. 172; L. Cerveró (1963), "Pintores valentinos: Su cronología y documentación», en Anales del Centro de Cultura Valenciana, p. 70; L. Cerveró (1965), «Pintores valentinos», Archivo de Arte Valenciano, p. 23, y L. Cerveró (1971), «Pintores valentinos», Archivo de Arte Valenciano, p. 24.

53. Estas noticias procedían de C. Martí I Vila (1959), «La devoció a Sant Baldiri (aspectes artístics)», Vida Samboyana, Sant Boi de Llobregat (maig), p. 15, que citaba a un tal Luis Almenara pintor junto a Lluís Dalmau. Sin embargo, fue J. M. Ainaud de Lasarte (1968), «Una taula documentada de Lluís Dalmau», Cuadernos de Arqueología e Historia de la Cindad, II (XII), p. 73-84, quien recogió la transcripción correcta de la documentación y lo relacionó con Bartomeu Almenar en la página 78.

54. M. Gómez-Ferrer (en prensa), La circulación de dibujos a mediados del siglo XV: Retrato social de la pintura valenciana a partir de las almonedas de Joan Moreno (1382-1448).

55. L. Cerveró (1965), «Pintores...», op. cit., p. 23.

56. S. Sanpere y Miquel (1906), «Los cuatrocentistas...», op. cit., p. 288 , mencionado en la compra de unas telas el 17 de abril de 1455 , junto a su esposa Isabel.

57. Estando aún en Valencia había formado una compañía con otro pintor cortinero, Tomás Rojales, a los que se había pagado 100 sueldos el 16 de marzo de 1447 por la entrega de unas cortinas (ACCV, Protocolos, Galcerán Gamiça, 24551).

58. J. M. Madurell y Marimon, El arte..., op. cit., p. 331. Ofrece también la noticia de que este pintor actuó como experto en la visura del retablo de Sant Pere de Pierola.

59. M. Gómez-Ferrer (2017), «Reflexiones sobre el pintor Jacomart: Un nuevo retablo de la Visitación (1455)», BSSA arte, 83, p. 11-28. 